\title{
RESOLUÇÃO DE PROBLEMAS DE COMBINATÓRIA UTILIZANDO MATERIAL DIDÁTICO E UM SIMULADOR INTERATIVO
}

Thalytta Evilly C. Silva (Autora), Universidade Federal de Campina Grande (UFCG), thalyttacavalcante@gmail.com

Andresso da Silva (Co-Autor), Universidade Federal de Campina Grande (UFCG), andresso.silva.42@gmail.com

Areli Mesquita da Silva (Orientadora), Universidade Federal de Campina Grande (UFCG), areli.mesquita@ufcg.edu.br

PALAVRAS-CHAVE: Resolução de Problemas de Contagem; Material Didático; Simulador Interativo.

KEY WORDS: Troubleshooting Counting; Courseware; Interactive Simulator.

PALABRAS CLAVE: Resolución de Problemas de Conteo; Material Didáctico; Simulador Interactivo.

\section{INTRODUÇÃO}

O ensino da Análise Combinatória no Ensino Fundamental e Médio apresenta uma série de dificuldades. Em geral, tais dificuldades surgem devido a utilização de procedimentos de cálculo com ênfase em aplicação automática e mecânica de fórmulas, sem estimular o raciocínio construtivo do aluno no processo ensino-aprendizagem, gerando uma certa aversão por este conteúdo. Diante disto, os professores de matemática buscam auxílios que possam contribuir para o ensino de Análise Combinatória em sala de aula do Ensino Fundamental e Médio, de modo a utilizar os conceitos matemáticos de forma mais eficiente, onde o aprendizado não fique limitado a quem tem facilidade nos cálculos, mas sim, que o mesmo seja acessível a todos. A implementação de novas propostas é fundamental, a fim de que o aluno venha a desenvolver estratégias para a resolução de problemas, adquirir levantamento de possibilidades, noções e conceitos que o ajudarão no discernimento e compreensão efetiva do conteúdo. A ideia é que o docente não fique preso às aulas tradicionais e sim utilize a dinâmica em sala de aula e o trabalho em equipe, facilitando o ensino-aprendizagem, tornando os alunos mais ativos e fazendo com que outras formas de ensino sejam contempladas, melhorando o rendimento dos alunos. A proposta deste trabalho consiste na apresentação de um material didático concreto, bem como de um simulador interativo, como ferramentas 
alternativas para facilitar o ensino-aprendizagem dos conceitos básicos da Análise Combinatória através da resolução de situações-problema do cotidiano, de modo que haja uma participação efetiva do aluno no processo ensino-aprendizagem, possibilitando ao mesmo o manuseio do material concreto e do simulador interativo para a construção e visualização da solução de problemas de contagem, dando ênfase à compreensão efetiva dos conceitos básicos da Combinatória e não ao uso automático e mecânico de fórmulas.

\section{METODOLOGIA}

Nesse trabalho, utilizamos a metodologia de ensino via resolução de problemas, sem a aplicação direta e mecânica de fórmulas, com o intuito de que os alunos compreendam os conceitos básicos da Análise Combinatória de maneira interativa e participativa. Para tanto, adquirimos um material concreto e construímos um simulador interativo. O simulador foi construído utilizando-se a linguagem de programação Processing.

\section{DESCRIÇÕES E INTERPRETAÇÕES}

O material concreto utilizado consiste de uma maquete de um ônibus (ver Figura 1), em MDF, com $50 \mathrm{~cm}$ de comprimento, $17,5 \mathrm{~cm}$ de largura e 21,5 $\mathrm{cm}$ de altura, comportando 25 assentos, sendo 1 assento do motorista e 24 assentos dos passageiros. Dentre os 24 assentos disponíveis, 4 são para uso exclusivo (idosos, gestantes, obesos e deficientes físicos). A maquete do ônibus é desmontável, facilitando a exploração da parte interna da mesma e a interação do aluno durante a resolução dos problemas (ver Figura 2). O interesse é utilizar os assentos para mostrar de quantas maneiras diferentes podemos alocar os passageiros, segundo algumas restrições.

Figura 1 - Foto da maquete do ônibus.

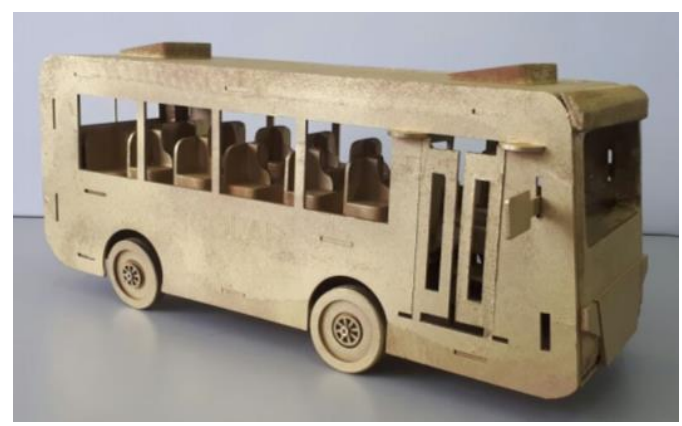

Fonte: própria orientadora. 
Figura 2 - Foto da maquete do ônibus sem o teto para facilitar exploração da parte interna.

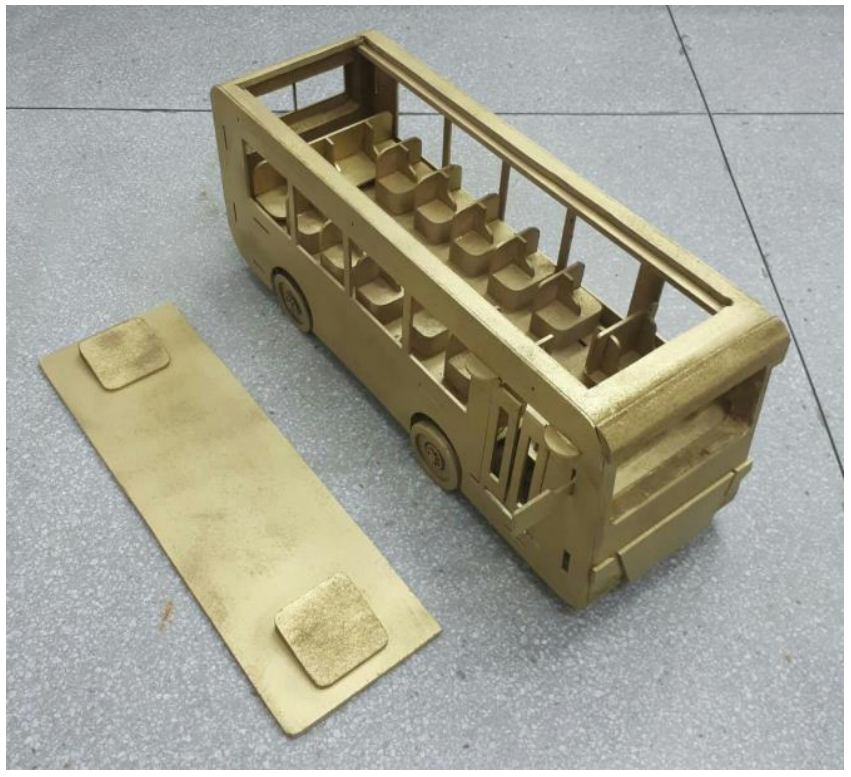

Fonte: própria orientadora.

O simulador interativo foi construído para a visualização das soluções dos problemas propostos, possibilitando a interação do aluno, facilitando a generalização do raciocínio utilizado. Na Figura 3 apresentamos a interface do simulador com uma situação-problema.

Figura 3 - Imagem da interface do simulador interativo.

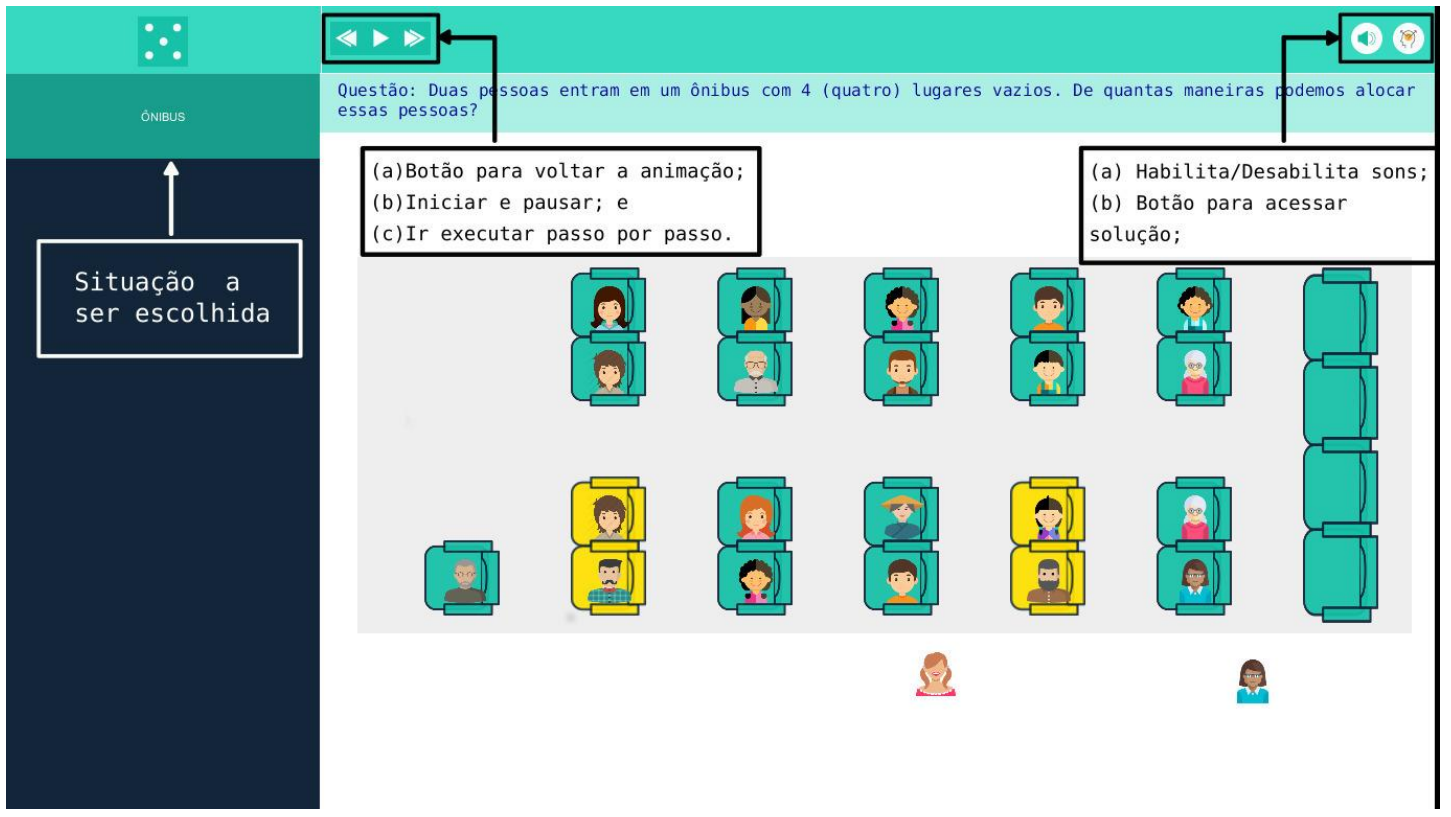

Fonte: própria orientadora.

Revista de Pesquisa Interdisciplinar, Cajazeiras, n. 2, suplementar, p. 783 - p. 792, set. de 2017. 
O simulador foi construído utilizando-se a linguagem de programação Processing. Segundo Reas e Fry (2014) o Processing é uma linguagem open-source voltada para estudantes, designers, artistas, arquitetos e pesquisadores e vem sendo utilizada em todo o mundo. Ela oferece suporte para animações com boa performance, exibição de imagens e áudio contando com a facilidade de utilização. É uma linguagem de alto nível, ou seja, o código é mais próximo da linguagem humana do que a linguagem de máquina, o que possibilita um alto nível de abstração. Assim, permite a programação orientada a objetos (POO) e este foi o paradigma utilizado nesse trabalho. O ambiente de programação (IDE) utilizado foi o oferecido pelos desenvolvedores do Processing. É possível também instalar biblioteca de terceiros. As utilizadas neste trabalho foram a CntrolP5 (versão 2.2.6) criada por Andreas Schlegel, a Combinatorics (versão 0.0.11) criada por Florian Jenett e G4P (versão 4.1.2) criada por Peter Lager. A primeira é uma interface gráfica de usuário (GUI) para a construção de interfaces gráficas customizadas. A segunda tem como objetivo fornecer um conjunto de classes e funções para a geração de combinações, arranjos e permutações.

Os problemas sugeridos nesse trabalho envolvem situações simples do cotidiano utilizando uma linguagem acessível, de modo que o aluno utilize os conhecimentos sobre combinatória como meio e não como fim, dando ênfase não apenas à resposta final, mas sim à forma de encontrá-la através do raciocínio, da reflexão e da criatividade.

Conforme Santos (2011, p. 72): “(...) o que ocorre, com frequência, no ensino da Análise Combinatória no ensino médio, é o uso excessivo de práticas manipulativas, levando o aluno à mecanização de processos", com isso "cria-se a falsa impressão de que a Análise Combinatória é somente um jogo de fórmulas complicadas” (MORGADO et al., 2004, p. 2). No entanto, utilizando-se a metodologia de ensino via resolução de problemas, o aluno é estimulado a racionar de maneira criativa de modo a construir estratégias para obter a solução dos mesmos. Neste sentido, os Parâmetros Curriculares Nacionais (PCNs) afirmam que:

Resolver um problema não se resume em compreender o que foi proposto e em dar respostas aplicando procedimentos adequados. Aprender a dar uma resposta correta, que tenha sentido, pode ser suficiente para que ela seja aceita e até seja convincente, mas não é garantia de apropriação do conhecimento envolvido. Além disso, é necessário desenvolver habilidades que permitam por à prova os resultados, testar seus efeitos, comparar diferentes caminhos, para obter a solução. Nessa forma de trabalho, o valor da resposta correta cede lugar ao valor do processo de resolução. $\mathrm{O}$ fato de o aluno ser estimulado a questionar sua própria resposta, a questionar o 
problema, a transformar um dado problema numa fonte de novos problemas, evidencia uma concepção de ensino e aprendizagem não pela mera reprodução de conhecimentos, mas pela via da ação refletida que constrói conhecimentos (BRASIL 1997, p. 33).

O objetivo é instigar o aluno, através da resolução de problemas, a observar certas regularidades ou padrões na solução dos problemas, de modo que o processo ensinoaprendizagem dos conceitos combinatórios ocorra de maneira natural, interativa, divertida e prazerosa. Segundo os Parâmetros Curriculares Nacionais para o Ensino Médio (PCNEM),

Se há uma unanimidade, pelo menos no plano dos conceitos entre educadores para as Ciências e a Matemática, é quanto à necessidade de se adotarem métodos de aprendizado ativo e interativo. Os alunos alcançam o aprendizado em um processo complexo, de elaboração pessoal, para o qual o professor e a escola contribuem permitindo ao aluno se comunicar, situar-se em seu grupo, debater sua compreensão, aprender a respeitar e a fazer-se respeitar; dando ao aluno oportunidade de construir modelos explicativos, linhas de argumentação e instrumentos de verificação de contradições; criando situações em que o aluno é instigado ou desafiado a participar e questionar; valorizando as atividades coletivas que propiciem a discussão e a elaboração conjunta de idéias e de práticas; desenvolvendo atividades lúdicas, nos quais o aluno deve se sentir desafiado pelo jogo do conhecimento e não somente pelos outros participantes. (BRASIL, 2000, p. $52)$.

Particularmente, na disciplina de Matemática, uma das estratégias de ensino sugerida é aquela baseada na resolução de problemas, como afirmam os Parâmetros Curriculares Nacionais para o Ensino Médio (PCNEM),

Não somente em Matemática, mas até particularmente nessa disciplina, a resolução de problemas é uma importante estratégia de ensino. Os alunos, confrontados com situações-problema, novas, mas compatíveis com os instrumentos que já possuem ou que possam adquirir no processo, aprendem a desenvolver estratégia de enfrentamento, planejando etapas, estabelecendo relações, verificando regularidades, fazendo uso dos próprios erros cometidos para buscar novas alternativas; adquirem espírito de pesquisa, aprendendo a consultar, a experimentar, a organizar dados, a sistematizar resultados, a validar soluções; desenvolvem sua capacidade de raciocínio, adquirem autoconfiança e sentido de responsabilidade; e, finalmente, ampliam sua autonomia e capacidade de comunicação e de argumentação (BRASIL, 2000, p. 52).

A compreensão dos conceitos envolvidos na Análise Combinatória é de extrema importância no desenvolvimento do raciocínio lógico matemático e na aquisição de capacidades essenciais para formação do indivíduo. Nos PCN+, a Análise Combinatória está 
inserida no eixo temático Análise de Dados, que pode ser organizado em três unidades temáticas: Estatística, Contagem e Probabilidade. Na unidade temática de Contagem os conteúdos e habilidades propostos para o $2^{\circ}$ ano do Ensino Médio são:

Contagem: princípio multiplicativo; problemas de contagem.

- Decidir sobre a forma mais adequada de organizar números e informações com o objetivo de simplificar cálculos em situações reais envolvendo grande quantidade de dados ou de eventos.

- Identificar regularidades para estabelecer regras e propriedades em processos nos quais se fazem necessários os processos de contagem.

- Identificar dados e relações envolvidas numa situação-problema que envolva o raciocínio combinatório, utilizando os processos de contagem (BRASIL, 2002, p. 127).

Ainda de acordo com os PCN+

A Contagem [...] permite também o desenvolvimento de uma nova forma de pensar em Matemática denominada raciocínio combinatório. Ou seja, decidir sobre a forma mais adequada de organizar números ou informações para poder contar os casos possíveis não deve ser aprendido como uma lista de fórmulas, mas como um processo que exige a construção de um modelo simplificado e explicativo da situação. As fórmulas devem ser consequência do raciocínio combinatório desenvolvido frente à resolução de problemas diversos e devem ter a função de simplificar cálculos quando a quantidade de dados é muito grande. Esses conteúdos devem ter maior espaço e empenho de trabalho no ensino médio, mantendo de perto a perspectiva da resolução de problemas aplicados para se evitar a teorização excessiva e estéril. Espera-se que assim o aluno possa se orientar frente a informações de natureza estatística ou probabilística. Nesse contexto, as calculadoras e o computador ganham importância como instrumentos que permitem a abordagem de problemas com dados reais ao mesmo tempo que o aluno pode ter a oportunidade de se familiarizar com as máquinas e os softwares. (BRASIL, 2002, p. 126 - 127).

Diante do exposto, a proposta desse trabalho é apresentar um material didático concreto e um simulador interativo como ferramentas alternativas para o ensinoaprendizagem dos conceitos básicos da Análise Combinatória através da resolução de situações-problema do dia-a-dia, estimulando a participação efetiva do aluno através do manuseio do material concreto e/ou do simulador interativo para a construção e visualização da solução de problemas de contagem, dando ênfase à compreensão efetiva dos conceitos básicos da Combinatória e não ao uso automático e mecânico de fórmulas, de modo que o aluno desenvolva o pensamento combinatório através da resolução de problemas que irão enfatizar o Princípio Fundamental de Contagem como principal estratégia de resolução. 
Inicialmente, apresentaremos problemas cuja resolução envolva um número pequeno de possibilidades, de modo que o aluno consiga construir, listar e visualizar cada uma delas. Em seguida, o aluno será questionado sobre o que aconteceria se modificássemos alguns parâmetros, estimulando-o a perceber que existe uma regularidade nesse tipo de problema, conduzindo-o à formalização e generalização do procedimento de resolução adotado. A ideia é levar o aluno a constatar, através do aumento gradativo do número de possibilidades de resultados, que a estratégia de listar cada uma dessas possibilidades torna-se muito cansativa e demorada, surgindo a necessidade de adotar estratégias mais eficientes de resolução que não dependam da listagem de todas as possibilidades. Ou seja, o aluno será estimulado a perceber a necessidade de generalizar o procedimento adotado na resolução do problema, com isso, a formalização da solução acontecerá gradativamente, de forma natural e construtiva.

Durante esse processo construtivo, o manuseio do material didático concreto possibilitará a visualização de cada umas das possibilidades de uma forma lúdica, ativa e interativa. Por outro lado, a utilização do simulador interativo facilitará a listagem das possibilidades à medida que as mesmas forem aumentando, auxiliando no processo de generalização do procedimento de uma forma bem natural e divertida. Assim, as fórmulas serão consequência do raciocínio combinatório desenvolvido através da resolução de problemas diversos e terão a finalidade de simplificar os cálculos quando a quantidade de possibilidades de resultados for muito grande.

A seguir apresentaremos um dos problemas dentre os vários que estarão disponíveis no simulador interativo, bem como algumas estratégias para a sua resolução.

PROBLEMA - Duas pessoas entram em um ônibus com 4 lugares vazios (ver Figura 3). De quantas maneiras podemos alocar essas pessoas?

SOLUÇÃO - A primeira estratégia para a resolução deste problema consiste em enumerar todas as possibilidades de ocupação de duas poltronas dentre as 4 que se encontram vazias. Para tanto, a utilização da maquete do ônibus, bem como do simulador interativo, será de grande importância para a visualização de todas as possibilidades, facilitando a listagem das mesmas. Observando a Figura 3, temos que as poltronas vazias são as de número 21, 22, 23 e 24, portanto as possibilidades de ocupação das mesmas são as seguintes: 


$\begin{array}{ll}\text { Poltronas 21 e 22; } & \text { Poltronas 23 e 21; } \\ \text { Poltronas 21 e 23; } & \text { Poltronas 23 e 22; } \\ \text { Poltronas 21 e 24; } & \text { Poltronas 23 e 24; } \\ \text { Poltronas 22 e 21; } & \text { Poltronas 24 e 21; } \\ \text { Poltronas 22 e 23; } & \text { Poltronas 24 e 22; } \\ \text { Poltronas 22 e 24; } & \text { Poltronas 24 e 23. }\end{array}$

Portanto, há 12 maneiras diferentes de alocarmos duas pessoas em 4 poltronas vazias.

Uma segunda estratégia de resolução deste problema consiste em construir uma árvore de possibilidades, indicando, no primeiro nível da mesma, as possíveis escolhas do primeiro passageiro e, no segundo nível, as possíveis escolhas do segundo passageiro, após o primeiro passageiro ter escolhido uma poltrona.

Possíveis escolhas do $1^{\circ}$ passageiro
Possíveis escolhas do $2^{\circ}$ passageiro

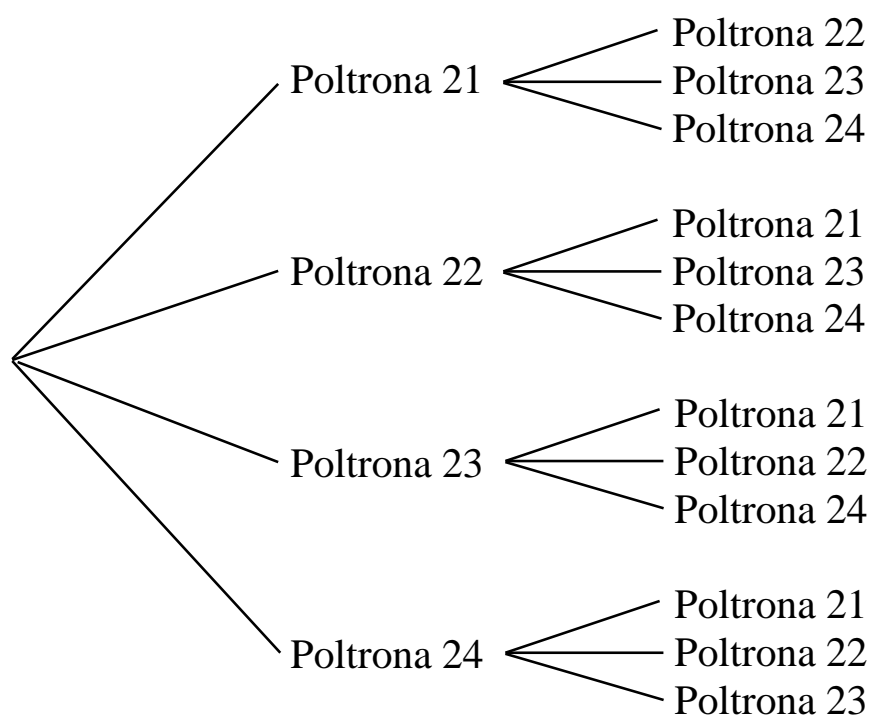

Todas as possibilidades

Poltrona 21 e Poltrona 22

Poltrona 21 e Poltrona 23

Poltrona 21 e Poltrona 24

Poltrona 22 e Poltrona 21

Poltrona 22 e Poltrona 23

Poltrona 22 e Poltrona 24

Poltrona 23 e Poltrona 21

Poltrona 23 e Poltrona 22

Poltrona 23 e Poltrona 24

Poltrona 24 e Poltrona 21

Poltrona 24 e Poltrona 22

Poltrona 24 e Poltrona 23

Neste tipo de estratégia, o aluno será estimulado a perceber que o $1^{\circ}$ passageiro terá 4 opções de escolha e que, para cada possível escolha do $1^{\circ}$ passageiro, haverá três opções de escolha para o $2^{\circ}$ passageiro, gerando, portanto, 12 maneiras diferentes desses dois passageiros ocuparem duas poltronas dentre as 4 vazias.

Após a construção da solução do problema através dessas estratégias, o aluno será instigado com as seguintes perguntas: o que aconteceria se o número de poltronas vazias fosse 5? Ou 6? Ou 24? E se o número de passageiros que entram no ônibus fosse 3? Ou 4? E assim 
por diante. A resposta para esses questionamentos será construída com o auxílio do simulador interativo, no qual será possível alterar cada uma dessas quantidades (tanto número de poltronas vazias quanto a quantidade de passageiros que entram no ônibus), de modo que o aluno perceba que existe uma certa regularidade nesses tipos de problemas e conduzindo a compreensão do Princípio Fundamental da Contagem, que consiste em multiplicar o total de opções de escolha para cada um dos passageiros. Por exemplo, para o problema enunciado na Figura 3, teríamos um total de $4 \times 3=12$ possibilidades.

Após a entendimento do Princípio Fundamental da Contagem, a ideia é que o aluno perceba que é possível resolver esse tipo de problemas sem a necessidade de listar cada umas das possibilidades, e isso é particularmente importante quando o número de possibilidades é muito grande, tornando desgastante e cansativa a listagem das mesmas.

\section{CONSIDERAÇÕES FINAIS}

A principal contribuição desse trabalho é apresentar ferramentas alternativas para o ensino da Análise Combinatória, com ênfase na resolução de problemas do cotidiano, a fim de desenvolver um raciocínio e senso crítico do aluno sobre como solucionar problemas de combinatória sem a aplicação imediata de fórmulas, facilitando assim o processo ensinoaprendizagem.

\section{REFERÊNCIAS}

BRASIL. Ministério da Educação. Secretaria de Educação Fundamental.

Parâmetros Curriculares Nacionais: Matemática. $\left(1^{\circ}\right.$ e $2^{\circ}$ ciclos do ensino fundamental). V.3. Brasília: MEC/SEF, 1997.

BRASIL. Secretaria de Educação Média e Tecnológica. Parâmetros Curriculares Nacionais - Ensino Médio (PCNEM): Ciências da Natureza, Matemática e suas Tecnologias. Brasília: MEC, 2000.

. Secretaria de Educação Média e Tecnológica. PCN+ Ensino Médio: Orientações Educacionais Complementares aos Parâmetros Curriculares Nacionais. Brasília: MEC, 2002.

MORGADO, A.C.; CARVALHO, J.B.P.; CARVALHO, P.C.P.; FERNANDEZ, P. Análise Combinatória e Probabilidade: com as soluções dos exercícios. 9 ed. Editora SBM: Rio de Janeiro, 2006. 
PEREIRA, A.G.C.; GOMES, C.A.; SIMIOLI, V. Introdução à Combinatória e

Probabilidade, Rio de Janeiro: Ciência Moderna Ltda, 2015.

REAS, C.; FRY, B. Processing: a programming handbook for visual designers and artists. 2. ed. Massachusetts: MIT Press, 2014.

SANTOS, J.P.O.; MELLO, M.P.; MURARI, I.T.C. Introdução à Análise Combinatória. Rio de Janeiro: Ciência Moderna Ltda, 2007.

SANTOS, Rafael Henrique dos. Uma Abordagem do Ensino da Análise Combinatória sob a Ótica da resolução de Problemas. 232p. Dissertação (Mestrado em Educação Matemática) - Universidade Cruzeiro do Sul, UCS-SP, São Paulo, 2011. 